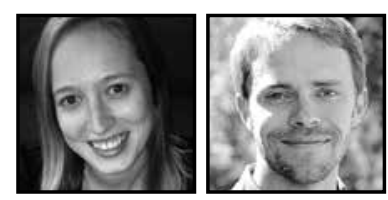

\title{
Bilingualism in the Early Years: What the Science Says
}

\author{
Krista Byers-Heinlein, Concordia University \\ Casey Lew-Williams, Northwestern University
}

\begin{abstract}
Many children in North America and around the world grow up exposed to two languages from an early age. Parents of bilingual infants and toddlers have important questions about the costs and benefits of early bilingualism, and how to best support language acquisition in their children. Here, we separate common myths from scientific findings to answer six of parents' most common questions about early bilingual development.
\end{abstract}

\section{Bilingualism in the Early Years: What the Science Says}

P ilingual parents are vocal in their desire to raise proficient, dynamic bilingual children. They have questions, and they want answers. But there is a complicated history of positive and negative press about raising children in bilingual households, to the point where some pediatricians_even today_recommend against exposing children to two languages. Attitudes against early bilingualism are often based on myths and misinterpretations, rather than scientific findings. Here, we aim to address the most frequently asked questions about childhood bilingualism using research findings from a variety of scientific fields including developmental psychology, cognitive psychology, education, linguistics, and communication sciences and disorders. This article is intended for parents and the many people who parents turn to for advice about fostering successful bilingual development: preschool teachers, elementary teachers, pediatricians, and speech-language pathologists. 
Bilingualism refers to the ability to use two languages in everyday life. Bilingualism is common and is on the rise in many parts of the world, with perhaps one in three people being bilingual or multilingual (Wei, 2000). Contact between two languages is typical in regions of many continents, including Europe (Switzerland, Belgium), Asia (India, Philippines), Africa (Senegal, South Africa), and North America (Canada). In the United States, a large (and growing) number of bilinguals live in California, Texas, Florida, New York, Arizona, and New Mexico. In California, for example, by 2035, it is expected that over $50 \%$ of children enrolled in kindergarten will have grown up speaking a language other than English (García, McLaughlin, Spodek, \& Saracho, 1995). Similarly, in some urban areas of Canada such as Toronto, up to $50 \%$ of students have a native language other than English (Canadian Council on Learning, 2008).

Despite the prevalence of bilingualism, surprisingly little research has been conducted on the topic, particularly on the foundations of bilingual language learning in infants and toddlers. The science of bilingualism is a young field, and definitive answers to many questions are not yet available. Furthermore, other questions are impossible to answer due to vast differences across families, communities, and cultures. But with an accumulation of research studies over the last few decades, we are now equipped to partially answer some of parents' most pressing questions about early bilingualism.

There are few venues for communicating scientific findings about early bilingualism to the public, and our goal is to distill bilingual and developmental science into practical, accessible information. We are researchers who study bilingual infants and children, and as such, we interact with bilingual families regularly. When we give community talks to preschools and nonprofit organizations about language development in early childhood, the question-and-answer period is invariably dominated by questions about early bilingualism. The consistency in questions is astonishing. Are bilingual children confused? Does bilingualism make children smarter? Is it best for each person to speak only one language with a bilingual child? Should parents avoid mixing languages together? Is earlier better? Are bilingual children more likely to have language difficulties, delays, or disorders? This article is organized around these six common questions.

\section{Are bilingual children confused?}

One of the biggest concerns that parents have about raising children in a bilingual household is that it will cause confusion. But is there any scientific evidence that young bilinguals are confused? The first question to ask is what confusion would look like. Except in the case of neurological disorders (Paradis, 2004), fluently bilingual adults can 
speak whatever language they choose in the moment, and are clearly not confused. But what about bilingual children and infants?

One misunderstood behavior, which is often taken as evidence for confusion, is when bilingual children mix words from two languages in the same sentence. This is known as code mixing. In fact, code mixing is a normal part of bilingual development, and bilingual children actually have good reasons to code mix (Pearson, 2008). One reason some children code mix is that it happens frequently in their language communities-children are just doing what they hear adults around them do (Comeau, Genesee, \& Lapaquette, 2003). A second reason is that, just like young monolinguals, young bilinguals are sometimes limited in their linguistic resources. Similarly to how a monolingual 1-year-old might initially use the word "dog" to refer to any four-legged creature, bilingual children also use their limited vocabularies resourcefully. If a bilingual child does not know or cannot quickly retrieve the appropriate word in one language, she might borrow the word from the other language (Lanza, 2004). Rather than being a sign of confusion, code mixing can be seen as a path of least resistance: a sign of bilingual children's ingenuity. Further, bilingual children do not seem to use their two languages haphazardly. Even 2-year olds show some ability to modulate their language according to the language used by their conversational partner (Genesee, Boivin, \& Nicoladis, 1996). There is also evidence that children's early code mixing adheres to predictable grammar-like rules, which are largely similar to the rules that govern adults' code mixing (Paradis, Nicoladis, \& Genesee, 2000).

What about bilingual infants? Again, the research is clear: bilingual infants readily distinguish their two languages and show no evidence of confusion. Languages differ on many dimensions-even if you don't speak Russian or Mandarin, you can likely tell one from the other. Infants are also sensitive to these perceptual differences, and are particularly attuned to a language's rhythm. Infants can discriminate rhythmically dissimilar languages like English and French at birth (Byers-Heinlein, Burns, \& Werker, 2010; Mehler et al., 1988), and by age 4 months they can tell even rhythmically similar languages like French and Spanish apart (Bosch \& Sebastián-Gallés, 1997, 2001; Nazzi, 2000). Bilingual infants may be even more sensitive than monolinguals when it comes to discriminating languages. Recent research has shown that 4-month-old monolingual and bilingual infants can discriminate silent talking faces speaking different languages (Weikum et al., 2007). However, by 8 months of age, only bilinguals are still sensitive to the distinction, while monolinguals stop paying attention to subtle variations in facial movements (Sebastián-Gallés, Albareda-Castellot, Weikum, \& Werker, 2012; Weikum et al., 2007). Instead of being confused, it seems that bilingual infants are sensitive to information that distinguishes their languages. 


\section{Does bilingualism make children smarter?}

Popular books such as The Bilingual Edge (King \& Mackey, 2009), and articles such as The Power of the Bilingual Brain (TIME Magazine; Kluger, 2013) have touted the potential benefits of early bilingualism. One of the most important benefits of early bilingualism is often taken for granted: bilingual children will know multiple languages, which is important for travel, employment, speaking with members of one's extended family, maintaining a connection to family culture and history, and making friends from different backgrounds. However, beyond obvious linguistic benefits, researchers have investigated whether bilingualism confers other non-linguistic advantages (Akhtar \& Menjivar, 2012).

Several studies have suggested that bilinguals show certain advantages when it comes to social understanding. In some ways, this is not surprising, as bilinguals must navigate a complex social world where different people have different language knowledge. For example, bilingual preschoolers seem to have somewhat better skills than monolinguals in understanding others' perspectives, thoughts, desires, and intentions (Bialystok \& Senman, 2004; Goetz, 2003; Kovács, 2009). Young bilingual children also have enhanced sensitivity to certain features of communication such as tone of voice (Yow \& Markman, 2011).

Bilinguals also show some cognitive advantages. In particular, bilinguals appear to perform a little bit better than monolinguals on tasks that involve switching between activities and inhibiting previously learned responses (Bialystok, Craik, \& Luk, 2012). Although these advantages have been mostly studied in bilingual adults (Costa, Hernández, \& Sebastián-Gallés, 2008) and children (Bialystok \& Martin, 2004), new evidence suggests that even bilingual infants (Kovács \& Mehler, 2009a, 2009b) and toddlers (Poulin-Dubois, Blaye, Coutya, \& Bialystok, 2011) show cognitive advantages. Additionally, there is some evidence that bilingual infants are advantaged in certain aspects of memory, for example generalizing information from one event to a later event (Brito \& Barr, 2012).

Research has not been able to determine exactly why these advantages arise, but there are several possibilities. Bilingual adults have to regularly switch back and forth between their languages, and inhibit one language while they selectively speak another. Some researchers suspect that this constant practice might lead to certain advantages by training the brain (Green, 1998). Amongst infants, the need to constantly discriminate their two languages could also play a role (Sebastián-Gallés et al., 2012). However, it is important to note that bilingualism is not the only type of experience that 
has been linked to cognitive advantages. Similar cognitive advantages are also seen in individuals with early musical training (Schellenberg, 2005), showing that multiple types of enriched early experience can promote cognitive development. Regardless of origin, it should be noted that the "bilingual advantage" has sometimes been overplayed in the popular press. So far, bilingual cognitive advantages have only been demonstrated using highly sensitive laboratory-based methods, and it is not known whether they play a role in everyday life. Thus, the reported advantages do not imply that bilingualism is an essential ingredient for successful development.

\section{Is it best for each person to speak only one language with a bilingual child?}

One popular strategy for raising bilingual children is "one-person-one-language," a strategy first recommended over 100 years ago (Ronjat, 1913). Theorists originally reasoned that associating each language with a different person was the only way to prevent bilingual children from "confusion and intellectual fatigue." While appealing, this early notion has been proven false. As discussed above, there is no evidence that bilingual children are confused by early bilingualism, and the cognitive benefits associated with bilingualism run counter to the notion of "intellectual fatigue."

It is still important to consider what strategies families can use to promote early bilingual development. Research has shown that a one-person-one-language approach can lead to successful acquisition of the two languages (Barron-Hauwaert, 2004), but that it does not necessarily lead to successful acquisition of the two languages (De Houwer, 2007). Further, children who hear both languages from the same bilingual parent often do successfully learn two languages (De Houwer, 2007). A one-person-one-language approach is neither necessary nor sufficient for successful bilingual acquisition.

Several other factors have proven to be important to early bilingual development. These factors might lead some families to use a one-person-one-language strategy, and other families to use other strategies. First, it is important to remember that infants learn language through listening to and interacting with different speakers. Infants need to have a lot of exposure to the sounds, words, and grammars of the languages that they will one day use. Both quality and quantity matter. High quality language exposure involves social interaction-infants do not readily learn language from television (DeLoache et al., 2010; Kuhl, Tsao, \& Liu, 2003), and low-quality television viewing in infancy has been linked to smaller vocabulary sizes in bilingual toddlers (Hudon, Fennell, \& Hoftyzer, 2013). Opportunities to interact with multiple different speakers has been linked to vocabulary learning in bilingual toddlers (Place \& Hoff, 2010). 
Quantity can be measured by the number of words that children hear per day in each language. Quantity of early exposure has a profound effect on children's ongoing language development: hearing more words gives children a greater opportunity to learn a language, which leads to later advantages in school performance (Hart \& Risley, 1995). For bilingual children, it is important to consider the quantity of their exposure to each language. While a bilingual's two languages do influence each other to a certain degree (Döpke, 2000), in many ways they travel on independent developmental paths. Bilingual children who hear a large amount of a particular language learn more words and grammar in that language (Hoff et al., 2012; Pearson \& Fernández, 1994), and show more efficient processing of that language (Conboy \& Mills, 2006; Hurtado, Grüter, Marchman, \& Fernald, 2013; Marchman, Fernald, \& Hurtado, 2010). Bilingual parents thus need to ensure that their children have sufficient exposure to the languages they want their children to learn. We return to this topic in the next sections.

Relatively balanced exposure to the two languages is most likely to promote successful acquisition of both of the languages (Thordardottir, 2011). In situations where each parent spends equal time with a child, one-parent-one-language can be a great way to ensure equal exposure. Conversely, exposure to a second language only when grandma and grandpa visit on the weekend, or when a part-time nanny visits on a few weekdays, or when a language class meets on Thursday nights, will not lead to balanced exposure. Imagine an average infant who sleeps about 12 hours a day, and so is awake 84 hours per week. A single afternoon ( 5 hours) is only about $6 \%$ of the child's waking life, and this exposure alone is unlikely to lead to acquisition of a language. Similarly, in homes where one parent is the primary caregiver, a one-parent-one-language is unlikely to lead to balanced exposure.

Unfortunately, providing perfectly balanced exposure in the early years will not necessarily ensure later bilingualism. As children become older, they become more aware of the language spoken in the community where they live, and are likely to use this language at school. This is known as the majority language, while other languages that are not as widely spoken are known as minority languages. Even if initially learned in preschool, minority languages are much more likely than majority languages to be lost as development continues (De Houwer, 2007). Many experts recommend providing slightly more early input in a minority than in a majority language, and where possible providing children with opportunities to play with other kids in that language (Pearson, 2008). Raising a bilingual child in communities that are largely bilingual such as Miami (Spanish-English), Montreal (French-English), and Barcelona (Catalan-Spanish) provides fewer challenges for ensuring the ongoing use of the two languages. 
So what language strategies should parents use? The best answer is that parents should use whatever strategy promotes high-quality and high-quantity exposure to each of their child's languages. This could include structured approaches such as using different languages as a function of person (one-person-one-language), place (one language at home, one language outside), or time (alternating days of the week, or mornings/afternoons). Some parents insist on speaking only one language with their child, even if they are able to speak the other (Lanza, 2004), to ensure exposure to a particular language. Other families find that flexible use of the two languages, without fixed rules, leads to balanced exposure and positive interactions. Each family should consider the language proficiency of each family member as well as their language preference, in conjunction with their community situation. Families should regularly make an objective appraisal of what their child is actually hearing on a daily basis (rather than what they wish their child was hearing), and consider adjusting language use when necessary.

\section{Should parents avoid mixing languages together?}

Many parents of bilingual children are bilingual themselves (Byers-Heinlein, 2013). Code mixing - the use of elements from two different languages in the same sentence or conversation-is a normal part of being a bilingual and interacting with other bilingual speakers (Poplack, 1980). Code mixing is relatively frequent amongst bilingual parents as well (Byers-Heinlein, 2013), and even parents who have chosen a one-parentone-language strategy still code mix from time to time (Goodz, 1989). But what effects does hearing code mixing have on the development of bilingual children?

Research on the impact of code mixing on bilingual children's development is still quite limited. One study of 18- and 24-month-olds found that high amounts of code mixing by parents was related to smaller vocabulary sizes (Byers-Heinlein, 2013). However, other studies have found no relationship between code-mixed language and early language development (Place \& Hoff, 2011). Further, studies are beginning to reveal that bilingual children as young as 20 -months are able to understand codemixed sentences, and show similar processing patterns as bilingual adults (ByersHeinlein, 2013). This would suggest that bilinguals are able to cope with code mixing from an early age. It has also been suggested that while code mixing might make word learning initially difficult, it is possible that practice switching back and forth between the languages leads to later cognitive benefits (Byers-Heinlein, 2013). Unfortunately, the jury is still out on whether exposure to code mixing has developmental consequences for bilingual children, but we are currently working on several research projects that will help answer this question. 
It is important to note that considerations of code mixing also have important social implications. In some communities, code mixing is an important part of being bilingual and being part of a bilingual community. For example, code mixing is the norm in some Spanish-English communities in the U.S., and Afrikaans-English code mixing is the norm in some parts of South Africa. Different communities have different patterns of and rules for code mixing (Poplack, 1984), and children need exposure to these patterns in order to learn them.

\section{Is earlier better?}

Many people are familiar with the concept of a "critical period" for language acquisition: the idea that humans are not capable of mastering a new language after reaching a certain age. Researchers disagree about whether a critical period exists at all, and they disagree about when this critical period may occur-proposals range from age 5 to 15 (Krashen, 1973; Johnson \& Newport, 1989; Lenneberg, 1967). Disagreement aside, research on bilingualism and second language learning converges robustly on a simple take-home point: earlier is better. There may not be a sharp turn for the worse at any point in development, but there is an incremental decline in language learning abilities with age (Birdsong \& Molis, 2001; Hakuta, Bialystok, \& Wiley, 2003).

This point is best understood as an interaction between biological and environmental factors. Researchers have argued that biological change during the first two decades of life results in a reduced capacity for learning and retaining the subtleties of language (Johnson \& Newport, 1989; Weber-Fox \& Neville, 2001). In other words, our brains may be more receptive to language earlier in life. But importantly, our environment is also more conducive to language learning earlier in life. In many cultures and in many families, young children experience a very rich language environment during the first years of life. They hear language in attention-grabbing, digestible bundles that are targeted skillfully at their developmental level (Fernald \& Simon, 1984). Caregivers typically speak in ways that are neither too simple nor too complex, and children receive hours and hours of practice with language every day. This high-quality and high-quantity experience with language-a special feature of how people communicate with young children-often results in successful language learning. It gives children rich, diverse, and engaging opportunities to learn about the sounds, syllables, words, phrases, and sentences that comprise their native language. But beyond the first years of life, second language learning often happens very differently. Older children and adults do not usually have the same amount of time to devote to language learning, and they do not usually experience the advantage of fun, constant, one-on-one interaction with native speakers. Instead, they often find themselves in a classroom, where they get a small 
fraction of the language practice that infants and toddlers get (Lew-Williams \& Fernald, 2010). In classrooms, words are defined for them and grammar is described to them. Defining and describing can be effective, but they are not as powerful as discovering language from the ground up.

Applied to bilingualism, these maturational and environmental differences between younger and older learners indicate that it is most advantageous to learn two languages early on in life. Bilinguals who learn two languages from birth are referred to as simultaneous bilinguals, and those who learn a first language followed by a second language-whether as toddlers or as adults - are referred to as sequential bilinguals. The evidence points to fairly robust advantages for simultaneous bilinguals relative to sequential bilinguals. They tend to have better accents, more diversified vocabulary, higher grammatical proficiency, and greater skill in real-time language processing. For example, children and adults who learn Spanish as a second language typically struggle to master Spanish grammatical gender (e.g., "is it el gato or la gato?"), while people who learn Spanish and English from birth show reliable and impressive ease in using grammatical gender (Lew-Williams \& Fernald, 2007, 2010).

However, parents should not lose hope if they have not exposed their children to each language from birth. Infants' brains and learning environments are special and non-recreatable, but there are many other ways to foster bilingual development. Here we overview two possibilities. First, some parents (particularly those who can afford childcare) choose to hire bilingual nannies or send children to bilingual preschools, in order to maximize their children's exposure to another language. This can certainly result in increased bilingual proficiency, but it is essential to provide continued opportunities to practice each language once the child is older. Parental expectations should be quite low if children do not have opportunities to continue learning and using a language throughout development. However, keep in mind that bilingual exposure does not necessarily translate to being a bilingual who is able to understand and speak a language fluently. Researchers generally consider a child to be bilingual if he or she receives at least $10-25 \%$ of exposure to each language (Byers-Heinlein, under review; Place \& Hoff, 2011; Marchman et al., 2010; Marchman, Martínez-Sussmann, \& Dale, 2004), but this level of exposure by no means guarantees functional bilingualism (De Houwer, 2007).

Second, there are language immersion programs in elementary schools in many of the world's countries, including the U.S. and Canada. Their goal is to promote bilingualism, biliteracy, and multicultural proficiency among both language-majority and language-minority students. In the U.S., hundreds of immersion programs have been 
established in the last four decades in such languages as Spanish, French, Korean, Cantonese, Japanese, Mandarin, Navajo, and Hebrew. There are currently 434 or more immersion programs in 31 U.S. states (Center for Applied Linguistics, 2011). French immersion programs are available in all 10 Canadian provinces, with enrolment ranging from 2-32\% of students depending on the province (Statistics Canada, 2000). Immersion programs confer advantages over other formats of language instruction that are typical in high school and college classrooms. In immersion programs, the second language is not necessarily a topic of instruction, but a vehicle for instruction of other curriculum subjects. In terms of the quantity of language exposure, immersion classrooms do not rival infants' language environments. However, they often foster functional bilingualism, and equip children with language skills that help them in later educational and professional contexts.

The take-home messages about bilingual language exposure are clear: more is better, and earlier is better. If you are 75 years old and you have always wanted to learn Japanese, start now. Language learning becomes more challenging with time, for both maturational and environmental reasons, but for those who are motivated (Gardner \& Lambert, 1959), it is never too late to learn a new language.

\section{Are bilingual children more likely to have language difficulties, delays, or disorders?}

Bilingual children are not more likely than monolingual children to have difficulties with language, to show delays in learning, or to be diagnosed with a language disorder (see Paradis, Genesee, \& Crago, 2010; Petitto \& Holowka, 2002). Parents' perceptions are often otherwise - they feel that their child is behind due to their bilingualism - revealing an interesting disconnect from scientific findings. Science has revealed an important property of early bilingual children's language knowledge that might explain this misperception: while bilingual children typically know fewer words in each of their languages than do monolingual learners of those languages, this apparent difference disappears when you calculate bilingual children's "conceptual vocabulary" across both languages (Marchman et al., 2010). That is, if you add together known words in each language, and then make sure you don't double-count cross-language synonyms (e.g., dog and perro), then bilingual children know approximately the same number of words as monolingual children (Pearson, Fernández, \& Oller, 1993; Pearson \& Fernández, 1994).

As an example, if a Spanish/English bilingual toddler knows 50 Spanish words and 50 English words, she will probably not appear to be as good at communicating when compared to her monolingual cousin who knows 90 English words. However, assuming 
10 of the toddler's Spanish words are also known in English, then the toddler has a conceptual vocabulary of 90 words, which matches that of her cousin. Even so, knowing 50 vs. 90 English words could result in noticeably different communication abilities, but these differences are likely to become less noticeable with time. This hypothetical example about equivalence in vocabulary is supported by research showing that bilingual and monolingual 14-month-olds are equally good at learning word-object associations (Byers-Heinlein, Fennell, \& Werker, 2013). This offers some reassurance that young bilinguals - like young monolinguals - possess learning skills that can successfully get them started on expected vocabulary trajectories. There is also evidence that bilingual children match monolinguals in conversational abilities; for example, when somebody uses a confusing or mispronounced word, or says something ambiguous, bilingual children can repair the conversation with the same skill as monolinguals (Comeau, Genesee, \& Mendelson, 2010).

Just like some monolingual children have a language delay or disorder, a similar proportion of bilinguals will have a language delay or disorder. Evidence that one bilingual child has a language difficulty, however, is not evidence that bilingualism leads to language difficulties in general. The challenge for pediatricians and for speech-language pathologists is to decide if a bilingual child does have a problem, or whether her errors are part of normal development and interaction between the sounds, words, and grammars of her two languages. If parents are worried that their bilingual child does have a delay, they should first consult their pediatrician. Pediatricians sometimes have a tendency to say, "Don't worry, her language is completely normal." This statement will end up being false for some children who will end up diagnosed with language difficulties, but it is more likely than not to be true, especially considering that parents can be inaccurate when estimating their bilingual child's language skills. In some other cases, health care providers with concerns about language impairment may recommend against raising a child in a bilingual environment. This recommendation is not supported by the science of bilingualism. Bilingual children with specific language impairments (Paradis, Crago, Genesee, \& Rice, 2003), Down syndrome (Kay-Raining Bird et al., 2005), and autism spectrum disorders (Peterson, Marinova-Todd, \& Mirenda, 2012) are not more likely to experience additional delays or challenges compared to monolingual children with these impairments.

If parents do not feel comfortable with a pediatrician's opinion, they should find (or ask for a referral to) a speech-language pathologist with expertise in bilingualism, if at all possible. Early intervention increases the likelihood of a positive outcome. The problem is that few clinicians receive quality training about the learning needs of bilingual children, which in some cases leads to a misdiagnosis of bilingual children as having 
delayed or disordered language (Bedore \& Peña, 2008; Kohnert, 2010; Thordardottir, Rothenberg, Rivard, \& Naves, 2006). The time is past due to eliminate such simple misunderstandings in clinical settings. A bilingual clinician, or an individual who has training in bilingualism, will take care in assessing language skills in both languages, in order to measure the child's entire language profile. Parents should keep in mind that clinicians have a very difficult job when it comes to assessing bilingual children. They have to (1) accurately assess a bilingual child's language abilities in each of her languages, (2) integrate the child's problematic and unproblematic abilities in terms of sounds, words, grammar, and conversation in each language into a coherent whole, (3) evaluate whether the child is delayed and/or disordered in one or both languages, (4) weigh the child's linguistic/cognitive capacities in comparison to typically and atypically developing monolingual children and, when possible, bilingual children of the same age, and (5) develop an effective intervention that targets subareas of linguistic/cognitive competence in one and/or both languages. This is a tangled landscape for intervention, but one that can be assessed thoughtfully. Regardless of whether parents pursue intervention, they can help children gain bilingual proficiency by using both languages as regularly as possible in enriching and engaging contexts. Furthermore, parents should keep in mind that both monolingual and bilingual children can best show off their skills when using language that matches their daily experiences (Mattock, Polka, Rvachew, \& Krehm, 2010).

In summary, if you measure bilinguals using a monolingual measure, you are more likely to find false evidence of delay. Fortunately, researchers and clinicians are now developing bilingual-specific measures that paint a more accurate picture of bilinguals' global language competence.

\section{Conclusion}

In this article, we have reviewed what the science says about six of parents' most commonly asked questions about early bilingualism. Research demonstrates that we need to reshape our views of early bilingualism: children are born ready to learn the language or languages of their environments without confusion or delay (Werker \& Byers-Heinlein, 2008). To promote successful bilingual development, parents raising bilingual children should ensure that their children have ample opportunities to hear and speak both of their languages. As children get older, interacting with monolingual speakers (especially other children) is important for motivating ongoing language use, especially for minority languages not widely spoken in the community (Pearson, 2008). 
Teachers, pediatricians, and speech language pathologists play an important role in dispelling common myths, and in communicating science-based information about early bilingualism to parents.

While our focus here has been on language development, it is also important to recognize that early childhood is also a time of profound emotional, social, physical, and cognitive development. Bilingualism will be a priority or even a necessity for some families. Other families might choose to focus on other aspects of development. In some cases, where families are not fluent in a second language, early bilingualism might be unrealistic. Here, it is important to keep two things in mind: 1) bilingualism is only one way to promote successful early development, and 2) second language learning is possible at any age. Language - any language - is a window to the world. It is better for parents to provide plenty of input and interaction in a language they are comfortable in, than to hold back because they are not fluent or comfortable in the language.

When it comes to raising bilingual children, myths and misunderstandings are common, but facts are hard to come by. Together with researchers around the world, we are working hard to continue providing scientifically based facts addressing parents' most important questions about early bilingualism.

\section{Acknowledgments}

This work was supported by grants to Krista Byers-Heinlein from the Natural Sciences and Engineering Council of Canada and the Fonds de recherche du Québec - Société et culture, and to Casey Lew-Williams from the National Institute of Child Health and Human Development and the American Speech-Language-Hearing Foundation. Thank you to Alexandra Polonia for her assistance with proofreading, and to the many parents of bilingual children whose questions inspire and motivate us. 


\section{References}

Akhtar, N., \& Menjivar, J. A. (2012). Cognitive and linguistic correlates of early exposure to more than one language. In J. B. Benson (Ed.), Advances in child development and behavior, Vol. 42 (pp. 41-78). Burlington: Academic Press.

Barron-Hauwaert, S. (2004). Language strategies for bilingual families: The one-parent-one-language approach. Clevedon, UK: Multilingual Matters.

Bedore, L. M., \& Peña, E. D. (2008). Assessment of bilingual children for identification of language impairment: Current findings and implications for practice. International Journal of Bilingual Education and Bilingualism, 11(1), 1-29. doi:10.2167/beb392.0

Bialystok, E., Craik, F. I. M., \& Luk, G. (2012). Bilingualism: consequences for mind and brain. Trends in Cognitive Sciences, 16(4), 240250. doi:10.1016/j.tics.2012.03.001

Bialystok, E., \& Martin, M. (2004). Attention and inhibition in bilingual children: Evidence from the dimensional change card sort task. Developmental Science, 7(3), 325-339. doi: 10.1111/j.1467-8624.2004.00693.x

Bialystok, E., \& Senman, L. (2004). Executive processes in appearance-reality tasks: The role of inhibition of attention and symbolic representation. Child Development, 75(2), 562579. doi: 10.1111/j.1467-8624.2004.00693.x

Birdsong, D., \& Molis, M. (2001). On the evidence for maturational constraints in secondlanguage acquisition. Journal of Memory and Language, 44(2), 235-249.

Bosch, L., \& Sebastián-Gallés, N. (1997). Nativelanguage recognition abilities in 4-monthold infants from monolingual and bilingual environments. Cognition, 65(1), 33-69. doi:10.1016/S0010-0277(97)00040-1

Bosch, L., \& Sebastián-Gallés, N. (2001). Evidence of early language discrimination abilities in infants from bilingual environments. Infancy, 2(1), 29-49. doi:10.1207/S15327078IN0201_3

Brito, N., \& Barr, R. (2012). Influence of bilingualism on memory generalization during infancy. Developmental Science, 15(6), 812816. doi:10.1111/j.1467-7687.2012.1184.x
Byers-Heinlein, K. (2013). Parental language mixing: Its measurement and the relation of mixed input to young bilingual children's vocabulary size. Bilingualism: Language and Cognition, 16(01), 32-48. doi:10.1017/ S1366728912000120

Byers-Heinlein, K. (under review). Methods for studying infant bilingualism. In J. W. Schwieter (Ed.), Cambridge handbook of bilingual processing. Cambridge, UK: Cambridge University Press.

Byers-Heinlein, K., Burns, T. C., \& Werker, J. F. (2010). The roots of bilingualism in newborns. Psychological Science, 21(3), 343-348. doi:10.1177/0956797609360758

Byers-Heinlein, K., Fennell, C.T., \& Werker, J.F. (2013). The development of associative word learning in monolingual and bilingual infants. Bilingualism: Language and Cognition, 16(1), 198-205. doi: 10.1017/ S1366728912000417

Canadian Council on Learning. (2008). Understanding the academic trajectories of ESL students. Retrieved from http://www. ccl-cca.ca/pdfs/LessonsInLearning/Oct-0208-Understanding-the-acedemic.pdf

Center for Applied Linguistics. (2011). Directory of Foreign Language Immersion Programs in U.S. Schools Summary of Data. Retrieved from http://www.cal.org/resources/immersion/

Comeau, L., Genesee, F., \& Lapaquette, L. (2003). The modeling hypothesis and child bilingual codemixing. International Journal of Bilingualism, 7(2), 113-126. doi:10.1177/13670 069030070020101

Comeau, L., Genesee, F., \& Mendelson, M. (2010). A comparison of bilingual monolingual children's conversational repairs. First Language, 30(3-4), 354-374. doi: $10.1177 / 0142723710$ 370530

Conboy, B. T., \& Mills, D. L. (2006). Two languages, one developing brain: Event-related potentials to words in bilingual toddlers. Developmental Science, 9(1), F1-F12. doi:10.1 $111 / \mathrm{j} .1467-7687.2005 .00453$ 
Costa, A., Hernández, M., \& Sebastián-Gallés, N. (2008). Bilingualism aids conflict resolution: Evidence from the ANT task. Cognition, 106(1), 59-86. doi:10.1016/j.cognition.2006.12.013

De Houwer, A. (2007). Parental language input patterns and children's bilingual use. Applied Psycholinguistics, 28(03), 411-424. doi:10.1017/S0142716407070221

DeLoache, J. S., Chiong, C., Sherman, K., Islam, N., Vanderborght, M., Troseth, G. L., et al. (2010). Do babies learn from baby media? Psychological Science, 21(11), 1570-1574. doi:10.1177/0956797610384145

Döpke, S. (Ed.). (2000). Cross-linguistic structures in simultaneous bilingualism. Amsterdam: Benjamins.

Fernald, F., \& Simon, T. (1984). Expanded intonation contours in mothers' speech to newborns. Developmental Psychology, 20(1), 104-113. doi:10.1037/0012-1649.20.1.104

García, E. E., McLaughlin, B., Spodek, B., \& Saracho, O. N. (1995). Yearbook in early childhood education. Vol. 6: Meeting the challenge of linguistic and cultural diversity in early childhood education. New York: Teachers College Press.

Gardner, R. C., \& Lambert, W. E. (1959). Motivational variables in second language acquisition. Canadian Journal of Psychology, 13(4), 266-272. doi:10.1037/h0083787

Genesee, F., Boivin, I., \& Nicoladis, E. (1996). Talking with strangers: A study of children's communicative competence. Applied Psycholinguistics, 17(4), 427-442. doi:10.1017/ S0142716400008183

Goetz, P. J. (2003). The effects of bilingualism on theory of mind development. Bilingualism: Language and Cognition, 6(1), 1-15. doi:10.1017/S1366728903001007

Goodz, N. S. (1989). Parental language mixing in bilingual families. Infant Mental Health Journal, 10(1). doi:10.1002/1097-0355 (198921)10:1<25::AID-IMHJ2280100104> 3.0.CO;2-R

Green, D. W. (1998). Mental control of the bilingual lexico-semantic system. Bilingualism: Language and Cognition, 1(02), 67-81. doi:10.1017/S1366728998000133
Hakuta, K., Bialystok, E., \& Wiley, E. (2003). Critical evidence: A test of the criticalperiod hypothesis for second-language learning. Psychological Science, 14(1), 31-38. doi:10.1111/1467-9280.01415

Hart, B., \& Risley, T. R. (1995). Meaningful differences in the everyday experience of young American children. Baltimore: Brookes.

Hoff, E., Core, C., Place, S., Rumiche, R., Señor, M., \& Parra, M. (2012). Dual language exposure and early bilingual development. Journal of Child Language, 39(1), 1-27. doi:10.1017/ S0305000910000759

Hudon, T. M., Fennell, C. T., \& Hoftyzer, M. (2013). Quality not quantity of television viewing is associated with bilingual toddlers' vocabulary scores. Infant Behavior and Development, 36(2), 245-254. doi:10.1016/j. infbeh.2013.01.010

Hurtado, N., Grüter, T., Marchman, V. A., \& Fernald, A. (2013). Relative language exposure, processing efficiency and vocabulary in Spanish-English bilingual toddlers. Bilingualism: Language and Cognition, 1-14. doi:10.1017/S136672891300014X

Johnson, J. S., \& Newport, E. L. (1989). Critical period effects in second language learning: The influence of maturational state on the acquisition of English as a second language. Cognitive Psychology, 21(1), 60-99. doi:10.1016/0010-0285(89)90003-0

Kay-Raining Bird, E., Cleave, P., Trudeau, N., Thordardottir, E., Sutton, A., \& Thorpe, A. (2005). The language abilities of bilingual children with Down syndrome. American Journal of Speech-Language Pathology, 14, 187-199. doi:1058-0360/05/1403-0187

King, K., \& Mackey, A. (2009). The bilingual edge. Ontario, Canada: HarperCollins.

Kluger, J. (2013, July). The power of the bilingual brain. TIME Magazine.

Kohnert, K. (2010). Bilingual children with primary language impairment: Issues, evidence and implications for clinical actions. Journal of Communication Disorders, 43(6), 456-473. doi:10.1016/j.jcomdis.2010.02.002

Kovács, Á. M. (2009). Early bilingualism enhances mechanisms of false-belief reasoning. Developmental Science, 12(1), 48-54. doi:10.1111/desc.2009.12.issue-1 
Kovács, Á. M., \& Mehler, J. (2009a). Cognitive gains in 7-month-old bilingual infants. Proceedings of the National Academy of Sciences, 106(16), 6556-6560. doi:10.1073/ pnas.0811323106

Kovács, Á. M., \& Mehler, J. (2009b). Flexible learning of multiple speech structures in bilingual infants. Science, 325(5940), 611-612. doi:10.1126/science.1173947

Krashen, S. (1973). Lateralization, language learning, and the critical period. Language Learning, 23, 63-74. doi:10.1111/ j.1467-1770.1973.tb00097.x

Kuhl, P. K., Tsao, F.-M., \& Liu, H.-M. (2003). Foreignlanguage experience in infancy: Effects of short-term exposure and social interaction on phonetic learning. Proceedings of the National Academy of Sciences, 100(15), 90969101. doi:10.1073/pnas.1532872100

Lanza, E. (2004). Language mixing in infant bilingualism: A sociolinguistic perspective. Oxford: Oxford University Press.

Lenneberg, E. H. (1967). Biological foundations of language. New York: Wiley.

Lew-Williams, C., \& Fernald, A. (2007). Young children learning Spanish make rapid use of grammatical gender in spoken word recognition. Psychological Science, 18(3), 193-198. doi:10.1111/j.1467-9280.2007.01871.x

Lew-Williams, C., \& Fernald, A. (2010). Real-time processing of gender-marked articles by native and non-native Spanish speakers. Journal of Memory and Language, 63(4), 447464. doi:10.1016/j.jml.2010.07.003

Marchman, V. A., Fernald, A., \& Hurtado, N. (2010). How vocabulary size in two languages relates to efficiency in spoken word recognition by young Spanish-English bilinguals. Journal of Child Language, 37(4), 817-840. doi:10.1017/S0305000909990055

Marchman, V. A., Martínez-Sussmann, C., \& Dale, P. S. (2004). The language-specific nature of grammatical development: Evidence from bilingual language learners. Developmental Science, 7(2), 212-224. doi:10. 1111/j.1467-7687.2004.00340.x

Mattock, K., Polka, L., Rvachew, S., \& Krehm, M. (2010). The first steps in word learning are easier when the shoes fit: Comparing monolingual and bilingual infants.
Developmental Science, 13(1), 229-243. doi:10.1111/j.1467-7687.2009.00891.x

Mehler, J., Jusczyk, P. W., Lambertz, G., Halsted, N., Bertoncini, J., \& Amiel-Tison, C. (1988). A precursor of language acquisition in young infants. Cognition, 29(2), 143-178. doi:10.1016/0010-0277(88)90035-2

Nazzi, T. (2000). Language discrimination by English-learning 5-month-olds: Effects of rhythm and familiarity. Journal of Memory and Language, 43(1), 1-19. doi:10.1006/ jmla.2000.2698

Paradis, J., Crago, M., Genesee, F., \& Rice, M. (2003). Bilingual children with specific language impairment: How do they compare with their monolingual peers? Journal of Speech, Language, and Hearing Research, 46, 1-15. doi:10.1017/S0142716407070300

Paradis, J., Genesee, F., \& Crago, M. B. (2010). Dual language development and disorders. Baltimore: Paul H Brookes Publishing Company.

Paradis, J., Nicoladis, E., \& Genesee, F. (2000). Early emergence of structural constraints on code-mixing: Evidence from French-English bilingual children. Bilingualism: Language and Cognition, 3(03), 245-261.

Paradis, M. (2004). A neurolinguistic theory of bilingualism. Amsterdam: John Benjamins Publishing Company.

Pearson, B. Z. (2008). Raising a bilingual child. New York: Random House.

Pearson, B. Z., \& Fernández, S. C. (1994). Patterns of interaction in the lexical growth in two languages of bilingual infants and toddlers. Language Learning, 44(4), 617-653. doi:10.1111/j.1467-1770.1994.tb00633.x

Pearson, B. Z., Fernández, S. C., \& Oller, D. K. (1993). Lexical development in bilingual infants and toddlers: Comparison to monolingual norms. Language Learning, 43(1), 93-120. doi:10.1111/j.1467-1770.1994. tb00633. $x$

Peterson, J., Marinova-Todd, S. H., \& Mirenda, P. (2012). Brief report: An exploratory study of lexical skills in bilingual children with autism spectrum disorder. Journal of Autism and Developmental Disorders, 42(7), 1499-1503. doi:10.1007/s10803-011-1366-y 
Petitto, L. A., \& Holowka, S. (2002). Evaluating attributions of delay and confusion in young bilinguals: Special insights from infants acquiring a signed and an oral language. Sign Language Studies, 3(1), 4-33.

Place, S., \& Hoff, E. (2011). Properties of dual language exposure that influence twoyear-olds' bilingual proficiency. Child Development, 82(6), 1834-1849. doi:10.1111/ j.1467-8624.2011.01660.x

Poplack, S. (1980). Sometimes I'll start a sentence in Spanish y termino en español: Toward a typology of code-switching. Linguistics, 18 , 581-618. doi:10.1515/ling-2013-0039

Poplack, S. (1984). Contrasting patterns of codeswitching in two communities (pp. 51-77). Presented at the Aspects of multilingualism.

Poulin-Dubois, D., Blaye, A., Coutya, J., \& Bialystok, E. (2011). The effects of bilingualism on toddlers' executive functioning. Journal of Experimental Child Psychology, 108(3), 567-579. doi:10.1016/j.jecp.2010.10.009

Ronjat, J. (1913). Le développement du langage observé chez un enfant bilingue. Paris: Champion.

Schellenberg, E. G. (2005). Music and cognitive abilities. Current Directions in Psychological Science, 14(6), 317-320. doi:10. 1111/j.0963-7214.2005.00389.x

Sebastián-Gallés, N., Albareda-Castellot, B., Weikum, W. M., \& Werker, J. F. (2012). A bilingual advantage in visual language discrimination in infancy. Psychological Science, 23(9), 994-999. doi:10.1177/0956797612436817

Statistics Canada. (2000). French Immersion 30 years later. Retrieved from www.statcan. gc.ca/pub/81-004-x/200406/6923-eng.htm
Thordardottir, E. (2011). The relationship between bilingual exposure and vocabulary development. International Journal of Bilingualism, 15(4), 426-445. doi:10.1177/ 1367006911403202

Thordardottir, E., Rothenberg, A., Rivard, M., \& Naves, R. (2006). Bilingual assessment: Can overall proficiency be estimated from separate measurement of two languages? Journal of Multilingual Communication Disorders, 4(1), 1-21. doi:10.1080/14769670500215647

Weber-Fox, C., \& Neville, H. J. (2001). Sensitive periods differentiate processing of openand closed-class words: An ERP study of bilinguals. Journal of Speech, Language and Hearing Research, 44(6), 1338-1353. doi:10.1044/1092-4388(2001/104)

Wei, L. (2000). Dimensions of bilingualism. In L. Wei (Ed.), The bilingualism reader (pp. 3-25). New York: Routledge.

Weikum, W. M., Vouloumanos, A., Navarra, J., Soto-Faraco, S., Sebastián-Gallés, N., \& Werker, J. F. (2007). Visual language discrimination in infancy. Science, 316(5828), 1159. doi:10.1126/science.1137686

Werker, J. F., \& Byers-Heinlein, K. (2008). Bilingualism in infancy: First steps in perception and comprehension. Trends in Cognitive Sciences, 12(4), 144-151. doi:10.1016/j. tics.2008.01.008

Yow, W. Q., \& Markman, E. M. (2011). Bilingualism and children's use of paralinguistic cues to interpret emotion in speech. Bilingualism: Language and Cognition, 14(4), 562-569. doi:10.1017/S1366728910000404 


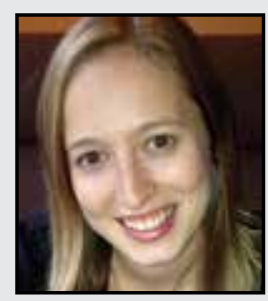

Krista Byers-Heinlein (B.A., McGill University; M.A., Ph.D., University of British Columbia) is Assistant Professor in the Department of Psychology at Concordia University. She directs the Concordia Infant Research Laboratory, and is a member of the Centre for Research in Human Development, and the Centre for Research on Brain, Language and Music. She is recognized internationally for her research on bilingualism in infancy, and has published extensively on the topics of bilingual infants' speech perception and word learning.

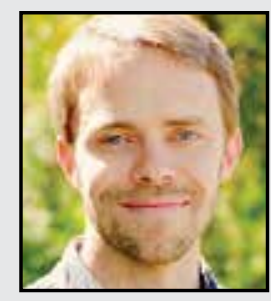

Casey Lew-Williams (B.A., University of California, Berkeley; M.A., Ph.D., Stanford University) is Assistant Professor in the Department of Communication Sciences and Disorders at Northwestern University. He directs the Language Learning Lab, a research group devoted to studying first, second, and bilingual language learning. His work focuses in particular on understanding how different learning experiences shape language outcomes in diverse populations of infants, children, and adults.

\section{LINK TO:}

http://infantresearch.concordia.ca

http://babylab.northwestern.edu 